\title{
Usability of Performance Dashboards, Usefulness of Operational and Tactical Support, and Quality of Strategic Support: A Research Framework
}

\author{
Bih-Ru Lea and Fiona Fui-Hoon Nah \\ Department of Business and Information Technology, Missouri University of Science \\ and Technology, Rolla, Missouri, USA \\ $\{$ leabi, nahf $\}$ amst. edu
}

\begin{abstract}
Performance dashboards are used as a strategic decision support tool in organizations. In this research, we examine the relationships between the usability of performance dashboards, the usefulness of operational and tactical support, and the quality of strategic support that they provide. We hypothesize that usability of performance dashboards will influence user perceptions of the usefulness of the operational and tactical support provided by the dashboards, which in turn influence the perceived quality of strategic support provided.
\end{abstract}

Keywords: Performance Dashboards, Usability, Data Visualization, Strategic Support, Tactical Support, Operational Support.

\section{Introduction}

Performance dashboards that are built on business intelligence platforms with integration tools to leverage rich data from a company's ERP systems play an important role in today's Executive Information Systems (EIS) (Watson, 2011). EIS facilitate and support executives in decision making to effectively and efficiently manage business activities such as planning, measuring, communicating, and monitoring business results. As the majority of executives, managers and decision makers are non-technical IT users with time constraints and tight schedule at work (Marx et al., 2011), visually appealing graphics rich performance dashboards that provide information in a user friendly format with virtually no learning curve play an important role in disseminating information effectively and efficiently.

Performance dashboards are often regarded as the modern version of EIS and are used to provide operational, tactical or analytical, and strategic support for management (Lea, 2012; Eckerson, 2011). As a variety of visual cues, graphs, gauges, icons, and images are utilized to provide visually appealing display in a performance dashboard (Few, 2006), usability of a performance dashboard becomes important because it can have an impact on the performance dashboard's usefulness in supporting decision making. This study hypothesizes that the usefulness of operational support and 
tactical support are influenced by the usability of performance dashboards and that the usefulness of operational and tactical support will have an impact on the quality of strategic support.

\section{$2 \quad$ Literature Review}

\subsection{Usability}

Various definitions of usability have been used in the literature. Nielsen (1994) defines usability as a quality attribute that assesses how easy it is to use a user interface. He defines usability based on five quality components (Nielsen, 2012):

- Learnability: How easy is it for users to accomplish basic tasks during first use?

- Efficiency: Once users have learned the design, how quickly can they perform tasks?

- Memorability: When users return to the design after a period of not using it, how easily can they re-establish proficiency?

- Errors: How many errors are made, how severe are these errors, and how easy is it to recover from the errors?

- Satisfaction: How pleasant is the interface?

Hence, Nielsen's definition of usability refers to how easy and pleasant an interface is. In this research, we will adopt Nielsen's definition and conceptualization of usability.

For completeness, we will review other common definitions and conceptualizations of usability and then justify why they are not adopted for this research.

The International Organization for Standardization (ISO 9241-11) defines usability as "The extent to which a product can be used by specified users to achieve specified goals with effectiveness, efficiency, and satisfaction in a specified context of use." (Karat, 1997, p. 34) The ISO definition of usability is not only specific to user and context, but it is also dependent on the goal. Since it can be difficult to accurately assess goals (i.e., even users may not be able to articulate their goals or may not be clear about their goals), not to mention assessing fulfillment of goals, we find the operationalization of ISO's definition of usability to be an empirical challenge. To date, we have not come across any empirical operationalization of usability as a formative construct comprising effectiveness, efficiency, and satisfaction, as suggested by ISO. Studies have assessed effectiveness, efficiency, and satisfaction but not having them as formative dimensions of usability.

Agarwal and Venkatesh (2002) used the Microsoft Usability Guidelines (MUG) to assess Web usability. The MUG are comprised of content (relevance, media use, depth and breadth, current and timely information), ease of use (relating to clear and understandable objectives, structure, and feedback), promotion (website advertising), made-for-the-medium (community, personalization, and refinement), and emotion (challenge, plot, character strength, and pace). Because of the multi-dimensionality of 
the MUG where not all criteria are equally important across different types of users and Web sites, evaluative criteria are needed to provide an assessment of the relative importance (or weights) of the different categories. Such evaluative criteria may be subjective and are dependent on a variety of factors such as user goals, user types, and types of interface. To remove subjectivity in determining the multidimensional assessment of usability, we will focus on ease of use in this research, which is in line with Nielsen's definition of usability.

\subsection{Usefulness}

Usefulness of decision support is an important construct for any system that offers decision support capabilities (Elbeltagi et al., 2005; Ruland and Bakken, 2002). In order for such a system to be accepted and adopted by users, the system needs to be perceived to be useful by users (Elbeltagi et al., 2005). In the context of this research, we will examine the perceived usefulness of different types of support presented by a performance dashboard.

\subsection{Dashboard}

A performance dashboard is defined as a multilayered interactive visual display mechanism built on a business intelligence and data integration infrastructure that conveys key performance information at a glance to allow users to effectively measure, monitor, and manage business performance of an organization toward predefined goals (Lea, 2012; Eckerson, 2011; Few, 2006). Similar to EIS, performance dashboards aim to deliver the right information to the right users at the right time in order to (i) optimize decision making, (ii) enhance operational efficiency (Lea, 2012), (iii) improve data visibility, process transparency, and strategy communication and alignment (Eckerson, 2011), (iv) reduce costs and resources required to prepare performance reports and management business (Eckerson, 2011; Pauwels et al., 2009), and (v) improve profitability.

Performance dashboards are often considered the successor of EIS (Few, 2006; Marx, et. al., 2011) and are regarded as one of the effective presentation layers of business intelligence as they are easily understood and require minimal or no training for users (Eckerson, 2011; Chaudhuri et al., 2011; Marx et al., 2011). Performance dashboards are commonly classified into three categories: Operational dashboards, Tactical, or Analytical dashboards, and Strategic dashboards to provide operational, tactical, and strategic decision support respectively (Lea 2012; Eckerson, 2011). Eckerson (2011) indicated that more than two thirds of survey respondents indicated that they use all three types of dashboards in their organizations with $80 \%$ in the form of tactical dashboards, $64 \%$ in the form of strategic dashboards, and $59 \%$ in the form of operational dashboards. Operation support focuses on monitoring business operations and activities through data visualization, results interpretation, report preparation, trends analysis, and flexibility to create additional charts, reports, and statistics, 
and thus often requires information with a high level of detail in real time or near real time. Tactical or analytical support utilize periodic snapshots of data to provide managers with functions to identify trends, patterns, or causes of problems to measure progress of their organization toward predefined goals, so traceability, accountability, communication, timely information, and flexibility in information details are key characteristics. Strategic support provides managers with tools to map the company's mission and strategies with objectives, measures, and initiatives and to monitor and communicate strategy execution (Kaplan and Norton, 1996).

An effective EIS implemented as a performance dashboard system enables vertical cascading and horizontal cascading for operational, tactical, and strategic support (Eckerson, 2009). Vertical cascading enables employees at all levels to understand how their efforts contribute to the company as a whole through the use of the same Key Performance Indicators (KPIs) across the dashboards of different levels. Horizontal cascading aligns the KPIs among all independent or interconnected dashboards to achieve the greatest degree of coordination possible and to bring together top-down strategic scorecard initiatives that can help to manage strategy with bottom-up dashboard projects that manage processes (Eckerson, 2009).

Vertical cascading and horizontal cascading could be operationalized through the use of three interconnected information layers: summarized graphical view, multidimensional analytical view, and detailed transactional data view (Eckerson, 2011) to present information differently or interactively for different users and for different purposes (Lea, 2012). Starting from the summarized graphical view (top layer), each successive layer provides additional details, views, and perspectives that help users to understand a problem better and to identify the steps needed to solve it, as shown in Fig. 1.

\section{Theoretical Background and Hypotheses}

The literature and empirical support on Technology Acceptance Model (TAM) has shown that usability (or ease of use) influences perceived usefulness (Davis, 1989). Marx et al. (2011) and Houdeshel and Watson (1987) suggested that ease of use is one of the key design principles for a successful EIS implemented as performance dashboards. As an extension of the prior literature, we hypothesize that usability (or ease of use) is a major factor influencing the perceived usefulness of operational and tactical support in the context of a performance dashboard. Hence, the following hypotheses are generated.

Hypothesis $1\left(\mathbf{H}_{1}\right)$ : Usability of a performance dashboard influences the perceived usefulness of operational support.

Hypothesis $2\left(\mathbf{H}_{2}\right)$ : Usability of a performance dashboard influences the perceived usefulness of tactical support.

As presented in the previous section, the strategic support provided by a performance dashboard relies on its operational and tactical support through the use of three interconnected information layers. In other words, a performance dashboard is a 


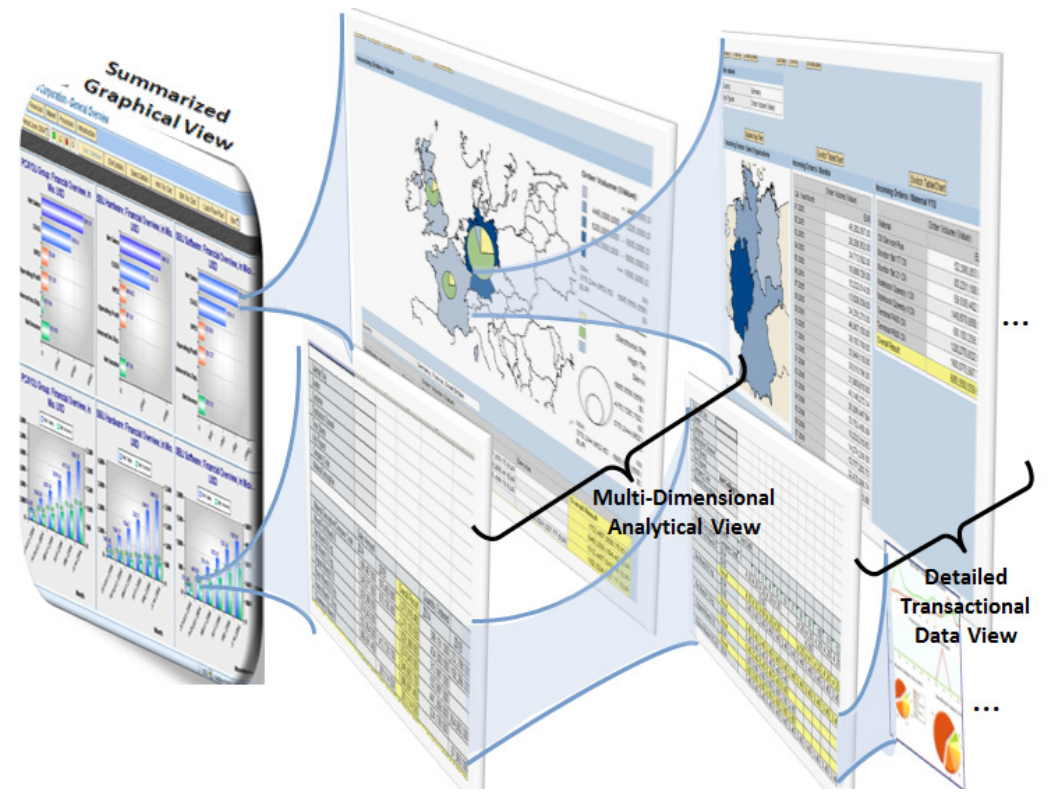

Fig. 1. Three Interconnected Information Layers in a Performance Dashboard

multilayered interactive visual display mechanism where its strategic support is built on the operational and tactical support provided. As illustrated in Fig. 1, in order to fully understand an item under strategic level support, one may need to drill into the tactical level or further into the operational level to fully understand the scenario. Hence, the quality of strategic support in a performance dashboard is influenced by the perceived usefulness of the operational and tactical support. As such, the following hypotheses are generated.

Hypothesis $3\left(\mathbf{H}_{3}\right)$ : Quality of strategic support is influenced by the perceived usefulness of operational support.

Hypothesis $4\left(\mathbf{H}_{\mathbf{4}}\right)$ : Quality of strategic support is influenced by the perceived usefulness of tactical support.

Fig. 2 presents these four hypotheses in a research model.

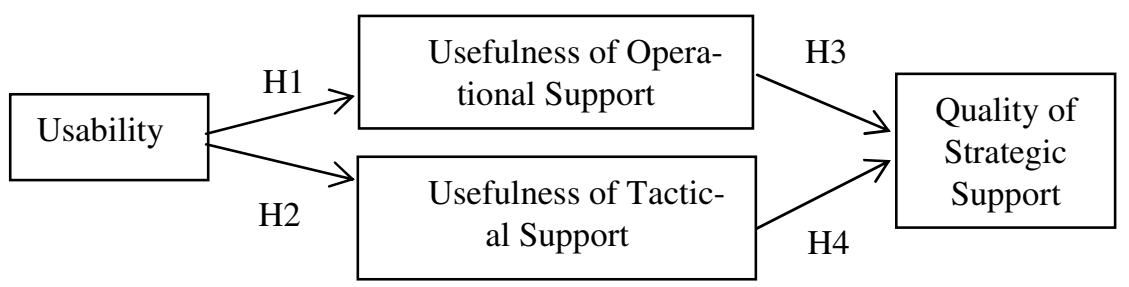

Fig. 2. Research Model 


\section{Methodology}

A user-friendly and interactive performance dashboard prototype was developed to facilitate a Midwest university's quest for AACSB accreditation through efficient and effective organization, manipulation, access and display of pertinent data. Informal feedback was requested periodically from the managing faculty within the Department seeking accreditation, the AACSB mentor, and the AACSB visiting team throughout the dashboard development process. Additionally, the dashboard was presented at numerous faculty meetings and faculty members were invited to attend the dashboard planning meetings to learn more about the dashboard and provide their input. After ensuring that the most important functionalities are provided in the dashboard prototype, a formal survey will be deployed to gather feedback to test the proposed hypotheses.

A sample screenshot of the performance dashboard is presented in Fig. 3.

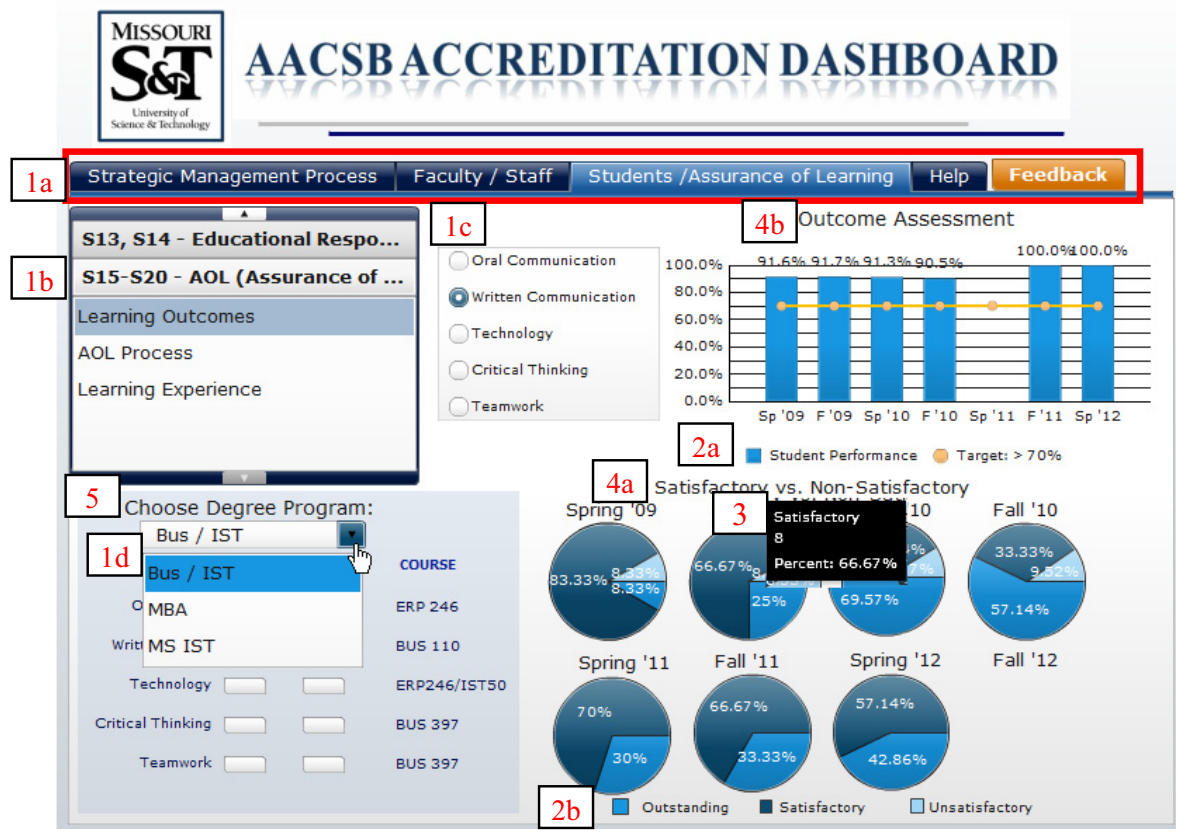

Fig. 3. Sample Screenshot of Performance Dashboard

User centric design principles were applied to ensure usability through ease of use, accessibility, learnability, and memorability. For example, information is categorize into different tabs, which are organized into a meaningful order and hierarchy as suggested by Marx et al (2011) and as shown in labels 1a, 1b, 1c, and 1d. A screen is typically divided into three or four sections to organize the information: a summarized and aggregated information section and two to three drill-down views to provide 
additional details based on user choices. Consistent layout design is maintained throughout all the tabs, making it easy for users to follow the design and to predict the effect of their actions. Color coding is used to represent the information content to make it easier for the user to understand the system and is kept consistent across different dashboard screens as shown in labels $2 a$ and $2 b$ in Fig. 3. Dynamic information tips are used when users move the cursor over an object to provide additional information or instruction of an object as shown in label 3 in Fig. 3. Common charts and diagrams are used to provide guided visual analysis (i.e., drill-down/drill across, slice and dice). Short and descriptive labels and explanations are provided for various information objects as shown in labels $4 \mathrm{a}$ and $4 \mathrm{~b}$ in in Fig. 3. Clear information is provided where users must select an option to display the information pertaining to that option as shown in label 5 in Fig. 3.

\section{$5 \quad$ Conclusions and Expected Contributions}

A survey will be conducted and the results will be reported at the conference. We expect the proposed hypotheses to be supported, where the quality of strategic support is dependent on the usefulness of operational and tactical support provided by the performance dashboard. We also expect the usability of the performance dashboard to influence the perceived usefulness of the operational and tactical support provided by the dashboard.

\section{References}

1. Agarwal, R., Venkatesh, V.: Assessing a Firm's Web Presence: A Heuristic Evaluation Procedure for the Measurement of Usability. Information Systems Research 13(2), 168186 (2002)

2. Chaudhuri, S., Dayal, U., Narasayya, V.: An Overview of Business Intelligence Technology. Communications of the ACM 54(8), 88-98 (2011)

3. Davis, F.D.: Perceived Usefulness, Perceived Ease of Use, and User Acceptance of Information Technology. MIS Quarterly 13(3), 318-340 (1989)

4. Eckerson, W.: Performance Management Strategies: How to Create and Deploy Effective Metrics. TDWI Best Practices Report (2009)

5. Eckerson, W.: Performance Dashboards: Measuring, Monitoring, and Managing Your Business, 2nd edn. Wiley Publishing (2011)

6. Elbeltagi, I., McBride, N., Hardaker, G.: Evaluating the Factors Affecting DSS Usage by Senior Managers in Local Authorities in Egypt. Journal of Global Information Management 13, 42-65 (2005)

7. Few, S.: Information Dashboard Design: The Effective Visual Communication of Data. O'Reilly, Sebastopol (2006)

8. Houdeshel, G., Watson, H.: The Management Information and Decision Support (MIDS) System at Lockheed-Georgia. MIS Quarterly 11(1), 127-140 (1987)

9. Kaplan, R., Norton, D.: Using the Balanced Scorecard as a Strategic Management System. Harvard Business Review, 150-161 (January-February 1996)

10. Karat, J.: Evolving the Scope of User-centered Design. Communications of the ACM 40(7), 33-38 (1997) 
11. Lea, B.-R., Beyond, E.R.P.: Enhancing Decision Making through Performance Dashboards and Scorecards. Pearson Publishing (2011)

12. Marx, F., Mayer, J., Winter, R.: Six Principles for Redesigning Executive Information Systems - Findings of a Survey and Evaluation of a Prototype. ACM Transactions on Management Information Systems 2(4), 26:1-26:19 (2011)

13. Nielsen, J.: Usability Engineering. Morgan Kaufmann Publishers (1994)

14. Nielsen, J.: Usability 101: Introduction to Usability. Jakob Nielsen's Alertbox (January 4, 2012),

http: / /www.nngroup.com/articles/usability-101-introductionto-usability/

15. Pauwels, K., Ambler, T., Clark, B.H., LaPointe, P., Reibstein, D., Skiera, B., et al.: Dashboards as a Service - Why, What, How, and What Research Is Needed? Journal of Service Research 12(2), 175-189 (2009)

16. Ruland, C.M., Bakken, S.: Developing, Implementing, and Evaluating Decision Support Systems for Shared Decision Making in Patient Care: A Conceptual Model and Case. Journal of Biomedical Informatics 35(5-6), 313-321 (2002)

17. Watson, H.: What Happened to Executive Information Systems? Business Intelligence Journal 16, 4-6 (2011) 